\title{
Tibia eminensia kırıklarında tedavi seçenekleri
}

\author{
Treatment options in tibial eminence fractures
}

\author{
Ahmet Bora Yeter ${ }^{1}$, A. Merter Özenci ${ }^{2}$ \\ ${ }^{1}$ Alanya Yaşam Hastanesi, Ortopedi Bölümü, Alanya, Antalya \\ ${ }^{2}$ Medical Park Hastanesi, Ortopedi Bölümü, Antalya
}

Tibia eminensia kırıkları her ne kadar çoğunlukla çocukluk ve adolesan dönemde görülen tipte kırıklar olsa da, nadir olarak erişkinlikte de görülebilir. Çoğunlukla direkt grafiler tanı için yeterli olsa da, eşlik eden yaralanmalar ve direkt grafinin yetersiz olduğu durumlarda manyetik rezonans görüntüleme ve bilgisayarlı tomografiden yararlanılabilir. En sık kullanılan sınıflama Meyers ve McKeever sınıflamasıdır. Günümüzde Tip 1 kırıkların tedavisi alçı ile immobilizasyon iken, Tip 2 kırıkların tedavisinde tartışmalar sürmektedir. Tip 3 ve 4 kırıkların ise neredeyse tamamına yakını cerrahi ile tedavi edilmektedir. 2000'lerden önce çıkan çalışmaların çoğu her ne kadar artroskopiyi sadece tanısal bir yöntem olarak görüp açık ameliyat yöntemlerini buna göre tanımlamış olsalar da, günümüzde eminensia kırıklarının çoğu artroskopik olarak tedavi edilebilmektedir. Eminensia kırıkları her ne kadar nadir de görülseler, son dönemde çocuklarda artan sportif aktivitelerle birlikte daha sık görülebilmektedir. Kırığın anatomik redükte edilerek ön çapraz bağ bütünlüğü ve boyunun korunması, stabil bir tespitin sağlanması tedavi sonucunu belirleyen en önemli etmenlerdir.

Anahtar sözcükler: tibia eminensia kırıkları; tedavi; artroskopi

\section{EMINENSIA KIRIKLARI PATOFIZYOLOJisi}

Tibia eminensia kırıkları her ne kadar çoğunlukla çocukluk ve adolesan dönemde görülen tipte kırıklar olsa da, literatürde 7 yaş ile 60 yaş arası görülebildiğini gösteren çalışmalar da mevcuttur. Tibia eminensia kırıkları, erişkinlikteki midsubstance ön çapraz bağ yırtıklarına eşdeğer kabul edilebilir. Tibial epifiz, kemik kısmının kemikleşmemesi nedeniyle ön çapraz bağın en zayıf kısmını oluşturur. Dolayısıyla, eminensia kırıkları anteromediyal tibial eminensia kısmındaki bağ insersiyo noktasından kondroepifizyel ayrışma ile gerçekleşir. ${ }^{[1-8]}$

\begin{abstract}
Although tibial eminence fractures are mostly seen in childhood and adolescents, it may also be seen in adulthood. X-rays are usually enough for the diagnosis. However, MRI and CT scan can be done for the associated injuries, and where the X-ray is not sufficient. Most common used classification is described by Meyers and McKeever. Nowadays, almost all of the type 1 fractures are treated conservatively. However, there is no consensus in the treatment of type 2 fractures. Almost all type 3 and 4 fractures are treated surgically. Arthroscopy was seen only as a diagnostic tool in most of the papers published before 2000's, but nowadays most of the eminence fractures are treated with arthroscopic techniques. Although eminence fractures are rarely seen, the incidence is increasing because of increasing sports activities in childhood and adolescents. Anatomic reduction of the fracture, protection of the integrity and length of the anterior cruciate ligament, and stable internal fixation are the most important parameters that affect prognosis.
\end{abstract}

Key words: tibia eminence fracture; treatment; arthroscopy

\section{EMINENSIA ANATOMISi}

Anatomik olarak, eminensia lateral ve mediyal tibial plato arasında yerleşerek mediyal ve lateral menisküsün bağları için yapışma noktası oluşturur. Triangüler yapıya sahip olup, çocuklukta tamamen kıkırdakla kaplıdır. Ön çapraz bağ, tibial eminensiaya anterior ve lateral dal olarak yapışır. Lateral menisküsün ön boynuzu tipik olarak yine bu bölgeye yapışır. Erişkinliğe doğru her ne kadar artiküler yüzey içermese de; serbest eklem faresi, ön çapraz bağın bütünlüğünün bozulması gibi sonuçları ele alındığında, eklem kırığı gibi değerlendirilir. ${ }^{[1-8]}$

- Illetişim adresi: Prof. Dr. A. Merter Özenci, Medical Park Hastanesi, Ortopedi Bölümü, Antalya

Tel: 0242 -3143434 e-posta: merteroz@yahoo.com

- Geliş tarihi: 1 Eylül $2018 \quad$ Kabul tarihi: 1 Eylül 2018 


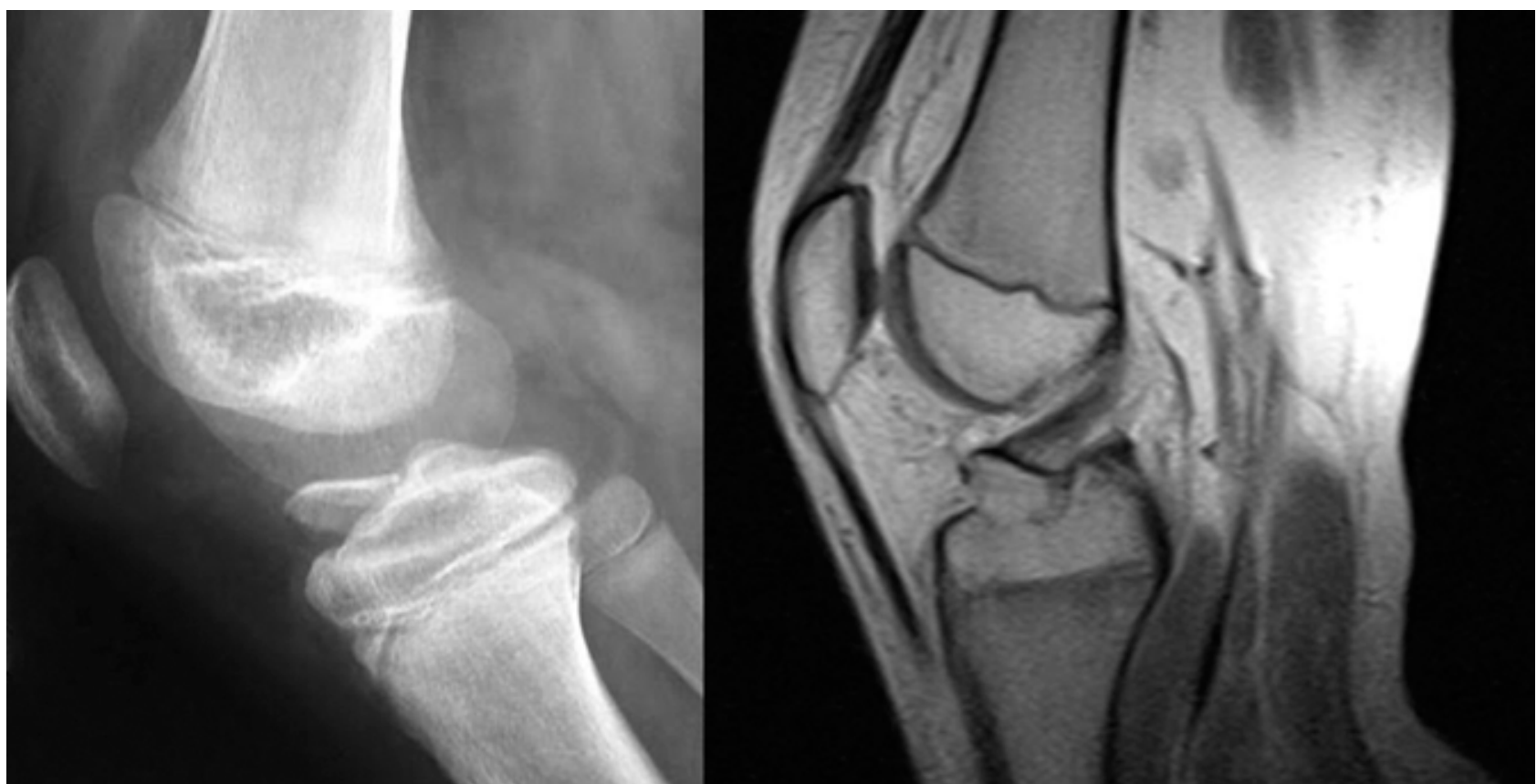

Şekil 1. On bir yaş erkek hastanın Tip 3B eminensia kırığı, direkt grafi ve MR görüntüleri.

\section{EPIDEMIYOLOJI VE YARALANMA MEKANIZMALARI}

Aslında çocuk kırıkları içerisinde de 100 000'de 3 ile oldukça nadir görülen bir kırık tipidir. Dolayısıyla gözden kaçırılma riski de yüksektir. Yaş grupları incelendiğinde en sık 8 ile 19 yaş grubu arasında görülmekle beraber, yaklaşık \%80'i 12 yaş altında saptanır. Oluşum mekanizması olarak, çocuklukta daha az enerjili bisiklet kazaları, atletik aktiviteler ve kayak saptanırken, erişkinlikte trafik kazaları gibi daha yüksek enerjili yaralanmalarda da görülür. Yapılan kadavra ve deneysel çalışmalar ile, traksiyonel kuvvetler ile benzeri yaralanmalar oluşturulabilmiştir. Yine aynı çalışmalar, midsubstance ön çapraz bağ yaralanmalarının yüksek yüklenme aşamalarında olduğunu gösterirken, tibial eminensia avulsiyon kırıklarının düşük yüklenme aşamalarında olduğunu göstermiştir. ${ }^{[1,6,9]}$

\section{FiZiK MUAYENE}

Hastayı doktora getiren nedenler; ağrı, şişlik, eklem hareketlerinde azalma ve ilgili ekstremite üzerine basamamadır. Fizik muayenede genellikle ciddi hemartrozla karşılaşılır. Ön çekmece, Lachman ve pivot-shift testleri müspet olsa da, sağlıklı muayene genellikle anestezi altında yapılabilir. Fizyolojik laksisite nedeniyle lateral ve mediyal kollateral bağlar dikkatli değerlendirilmeli ve gerekirse diğer ekstremite ile kıyaslama yapılmalıdır. Muayenede genellikle kemik bloğu nedeniyle ekstansiyon kısıtlılığı izlenir. ${ }^{[1,6,9,10-15]}$

\section{RADYOLOJiK INCELEME YÖNTEMLERi}

Çekilen direkt grafilerde en iyi görüş lateral ve tünel grafilerinde sağlansa da avulsiyon kırık bölgesi ince kemikleşmiş parça içeren non-ossifiye kıkırdak şeklinde olabilir ve bu direkt grafilerde görülmeyi zorlaştırabilir. Eşlik edebilecek menisküs ve kollateral bağ yaralanmalarının tespiti için ya da ufak avulsiyon kırıklarının görüntülenmesi için manyetik rezonans (MR) görüntülemeden ve adolesanlarda yüksek enerjili kırıklarda bilgisayarlı tomografiden (BT) yararlanılabilir (Şekil 1 ve 2). ${ }^{[4-12]}$

\section{SINIFLAMA}

En sık kullanılan sınıflama Meyers ve McKeever sınıflamasıdır. Daha sonra Zaricznyj bu sınıflamaya bir tip daha eklemiştir. Bu sınıflamaya göre; Tip 1 kırıklarda deplasman yok iken, Tip 2 kırıklarda ön $1 / 3$ veya $1 / 2$ kısım deplase olarak izlenir. Tip 3 kırıklarda ise parça tamamen deplase izlenir. Daha sonra geliştirilen alt gruplamaya göre; Tip 3A kırıklar tamamen deplase iken, Tip 3B kırıklarda deplasman ve rotasyon mevcuttur. Tip 4 kırıklar ise deplase ve paçalıdır. Direkt 


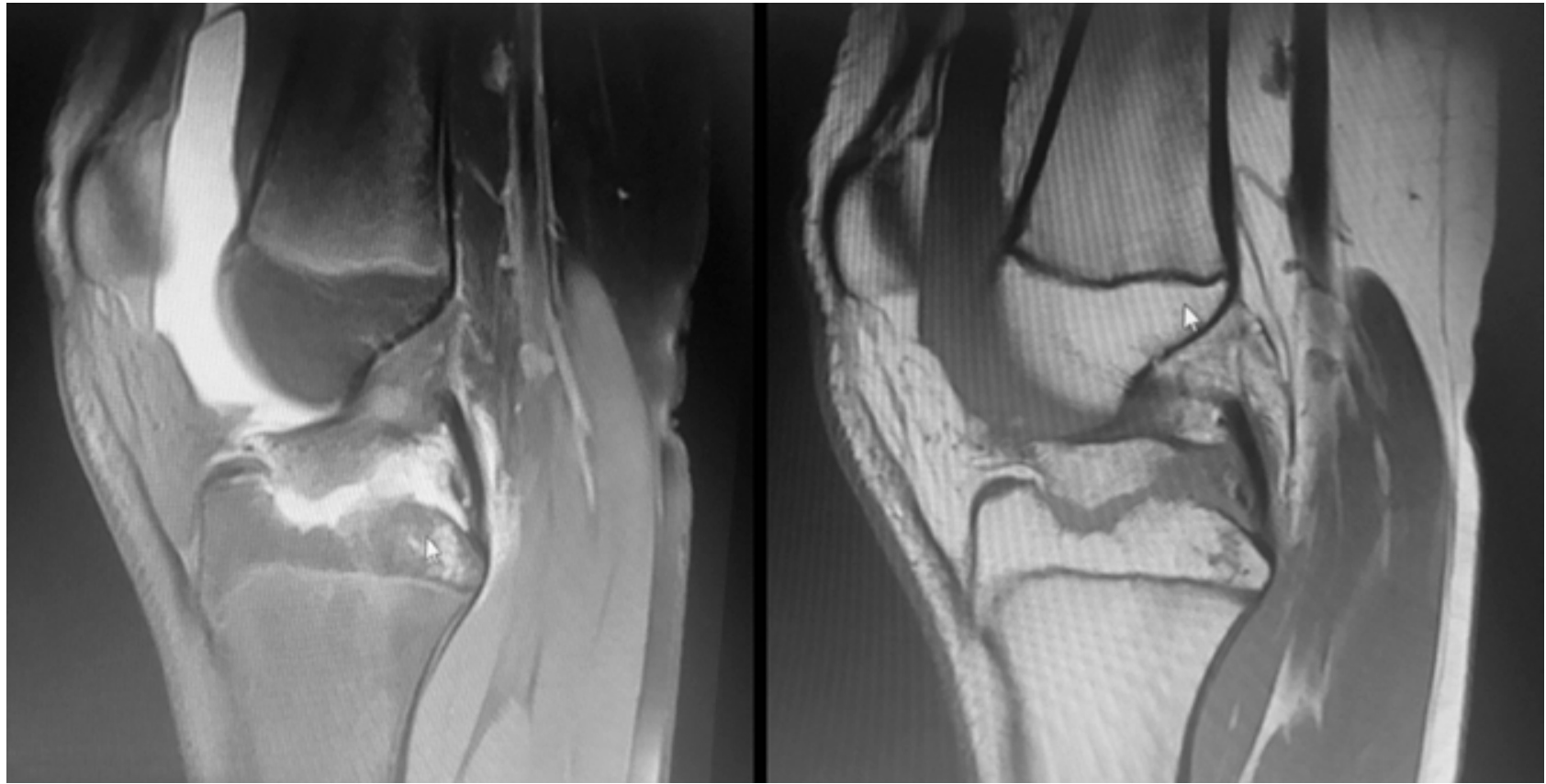

Şekil 2. On üç yaş, erkek hastanın Tip 3A tibia eminensia kırı̆̆ı, pre-op MR görüntüleri.

grafide genellikle düzgün değerlendirme yapılabilse de, bazı çalışmalarda Tip 4 kırıklar ancak artroskopik görünüm sonucu net değerlendirilebilmiştir. Yine bazı çalışmalar da artroskopiyi bir tanısal yöntem olarak kullanmışlardır. Artroskopi, eşlik eden yaralanmaların saptanmasında da kullanılabilir (Şekil 3). ${ }^{[1,3]}$

\section{EŞLiK EDEN YARALANMALAR}

Eşlik eden yaralanmalar her ne kadar nadir de görülse, en sık saptanan menisküs yaralanmalarıdır. Bu meniskal yaralanmalar kırık hattına girerek blokaj oluşturup, kırık parçanın redükte edilmesini engelleyebilir. Kollateral bağ yaralanmaları da yine daha nadir olarak eşlik edebilir. ${ }^{[4,7,9,16,17]}$

\section{TEDAVI SEÇENEKLERi}

Meyers ve McKeever, 1959'da emiensia kırık sınıflamasını yayımladıkları dönemde, eminensia kırıkları tedavisini hiperekstansiyonda manipülasyonu takiben immobilizasyon olarak tanımlamışlardı. Bunun yanında, Tip 3 kırıklarda cerrahi seçeneği de vurgulamışlardı. ${ }^{[1]}$

Günümüzde Tip 1 kırıkların tedavisi alçı ile immobilizasyon iken, Tip 2 kırıkların tedavisinde tartışmalar sürmektedir. Tip 3 ve 4 kırıkların ise neredeyse tamamına yakını cerrahi ile tedavi edilmektedir. Tip 2 ve 3 kırıklarda aspirasyon ve kapalı redüksiyon sonrası konservatif tedavi önerenler olduğu gibi, cerrahi tedavi uygulayanlar da mevcuttur. Kapalı redüksiyon Tip 2 kırıkların bazılarında başarılı olurken, Tip 3 kırıklarda bu oran düşer ve çoğunluğu cerrahi ile tedavi edilir. ${ }^{[1,7,18]}$

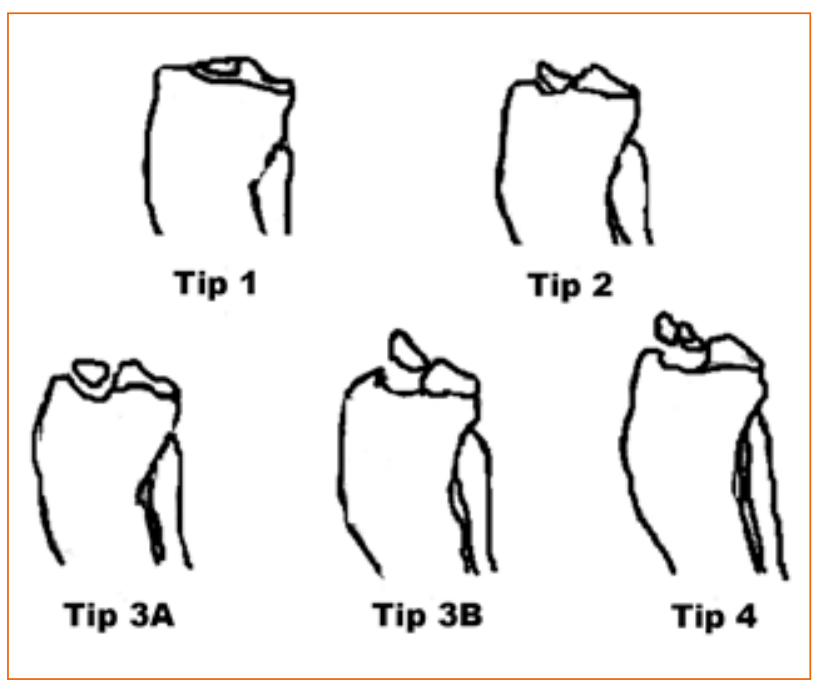

Şekil 3. Meyers ve McKeever sınıflaması. 


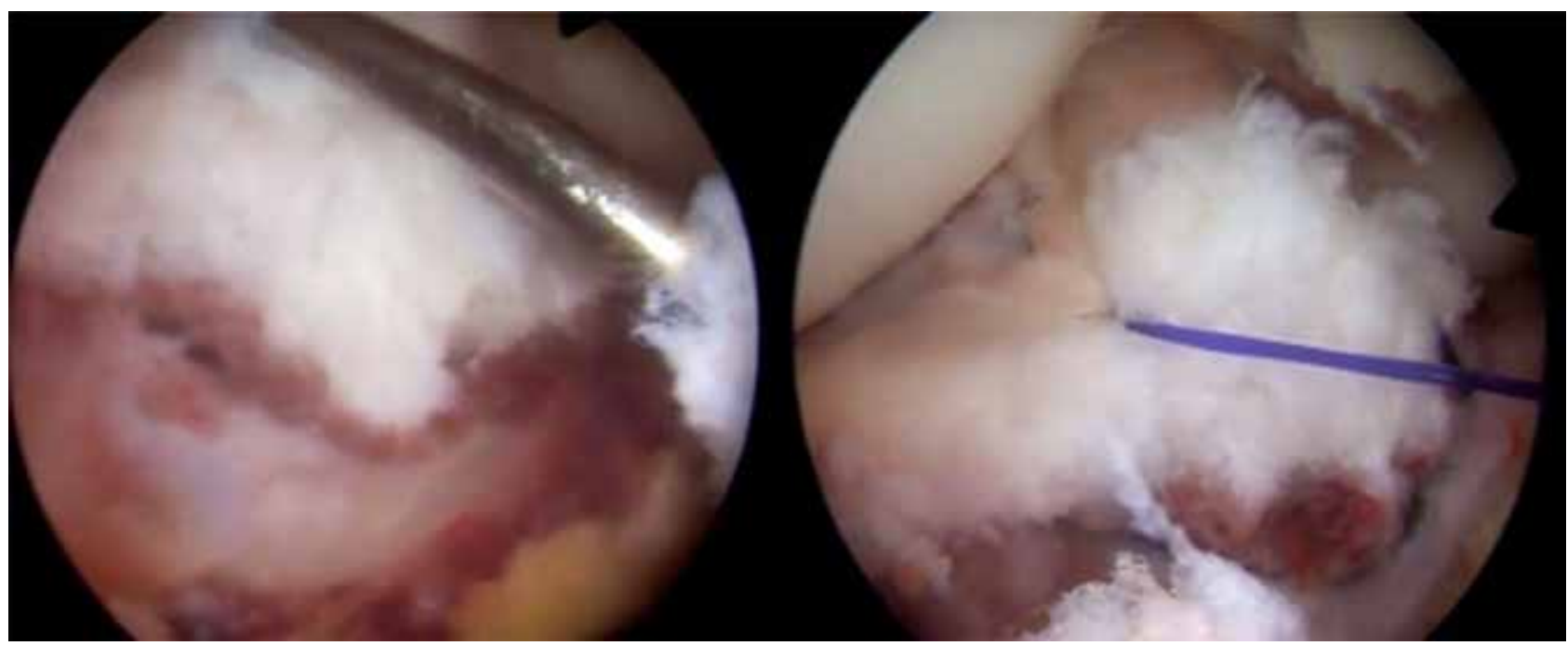

Şekil 4. Şekil 2'deki olgunun artroskopik görüntüleri: Redüksiyon öncesi ve PDS sütürle onarımı. İki adet PDS sütür tibia ön yüzden eklem içine ilerletilerek ön çapraz bağ içinden geçirilmiş ve tibia ön yüzde düğümlenmiştir. Herhangi bir implant kullanılmamıştır.

Kapalı tedavi öncesi diz içerisindeki geniş hematom mutlaka boşaltılarak, diz tam ekstansiyona veya $20-30^{\circ}$ arası fleksiyona getirilmeli ve skopi görüntüleri ile redüksiyon gözlemlenmelidir. Parça ne kadar büyük olursa kapalı redükte olma şansı o kadar artar. Kırık hattı mediyal ya da lateral platoya uzanıyorsa, tam ekstansiyon mediyal ya da lateral femoral kondilin uyguladığı baskı nedeniyle redüksiyonu etkileyebilir. Dolayısıyla, interkondiller çentikle sınırlı kırık bu anlamda etkilenmez. İntermeniskal bağ ya da mediyal ve lateral menisküsün kırık hattı arasına girerek redüksiyonu engelleme ihtimali akılda bulundurulmalıdır. ${ }^{[7,9,10,18,19]}$

Kapalı olarak tedavi edilen hasta grubuna alçı bakımı anlatılarak kırık hattında kayma 1-2 haftalık dönemlerle takip edilmelidir. Alçı 4-6 hafta arasında çıkarılmalı ve fonksiyonel açı ayarlı diz ortezine geçilerek fizik tedaviye başlanmalıdır. Spor aktivitelerine ortalama dönüş zamanı üç aydır. ${ }^{[7,9,10,18,19]}$

Çoğu Tip 2, 3 ve 4 kırık tipi redükte olmaz ve kırık hattına potansiyel menisküs sıkışması, potansiyel instabilite ve ekstansiyon kısıtlılığı, eşlik eden osteokondral lezyon, meniskal yaralanmalar gibi nedenlerle, cerrahi olarak tedavi edilir. Cerrahi tedavi ile, erken mobilizasyon da avantajlardan biridir. Yapılan çalışmalar, kırık deplasmanı ile diz laksisitesi ve fonksiyonel sonuç arasında anlamlı fark saptamışlardır. ${ }^{[4,12,19-21]}$

Tip 3 ve 4 kırıkların çoğu cerrahi yaklaşımla tedavi edilir. Ancak, burada esas tartışma Tip 2 kırıkların tedavisindedir. Yüzde 62'yi bulan intermeniskal bağ interpozisyonu, erken mobilizasyon şansı ve mediyal tibial platoya uzanımın fazla olması, Tip 2 kırıkların cerrahi tedavi edilme olasılı̆̆ını arttırır. ${ }^{[20]}$

2000'lerden önceki çalışmaların çoğu, her ne kadar artroskopiyi tanısal bir yöntem olarak görüp açık ameliyat yöntemlerini buna göre tanımlamış olsalar da, günümüzde eminensia kırıklarının çoğu artroskopik olarak tedavi edilebilmektedir. Yetersiz tespit ve teknik olarak yapılması daha zor olarak gösterildiyse de, daha az morbidite, daha az skar ve daha hızlı iyileşme artroskopik tedavi yöntemlerini ön plana çıkarmıştır. ${ }^{11,3,4,7-9,14,15,18-24]}$

Fiksasyon tiplerini ise kabaca iki ana grupta incelemek mümkündür: sütür ile onarım ve vida ile onarım. Sütür ile onarım yönteminde; avulsiye kemik parça proksimalinden ve ön çapraz bağ içinden sütür geçilerek tibial tüberositenin mediyalinden yapılan miniinsizyon ile kemik eksplore edilerek kırık yatağı mediyal ve lateralinden geçecek şekilde iki delme işlemi ile sütür bu tünellerden alınır ve tibia ön yüzde dügüumlenir. Tibial tespitte U-stapler ve vida kullanımı da tanımlanmıştır. Ancak, bu durumda implant çıkarımı gerekebilir (Şekil 4). ${ }^{[6,11,12,19]}$

Diğer bir tespit yöntemi ise bir veya iki kanüle vida kullanımıdır. Bu yöntemde, kırık parçanın tutturulması esnasında parçalanması olasıdır. Pul kullanımını ile bu olasılık azaltılabilir. Vida kullanımındaki en önemli gerekçe daha stabil bir tespit sağlanması olmakla beraber, parçalı kırıklarda bu durum mümkün olmayabilir. Bir diğer tartışma konusu ise fizisin 


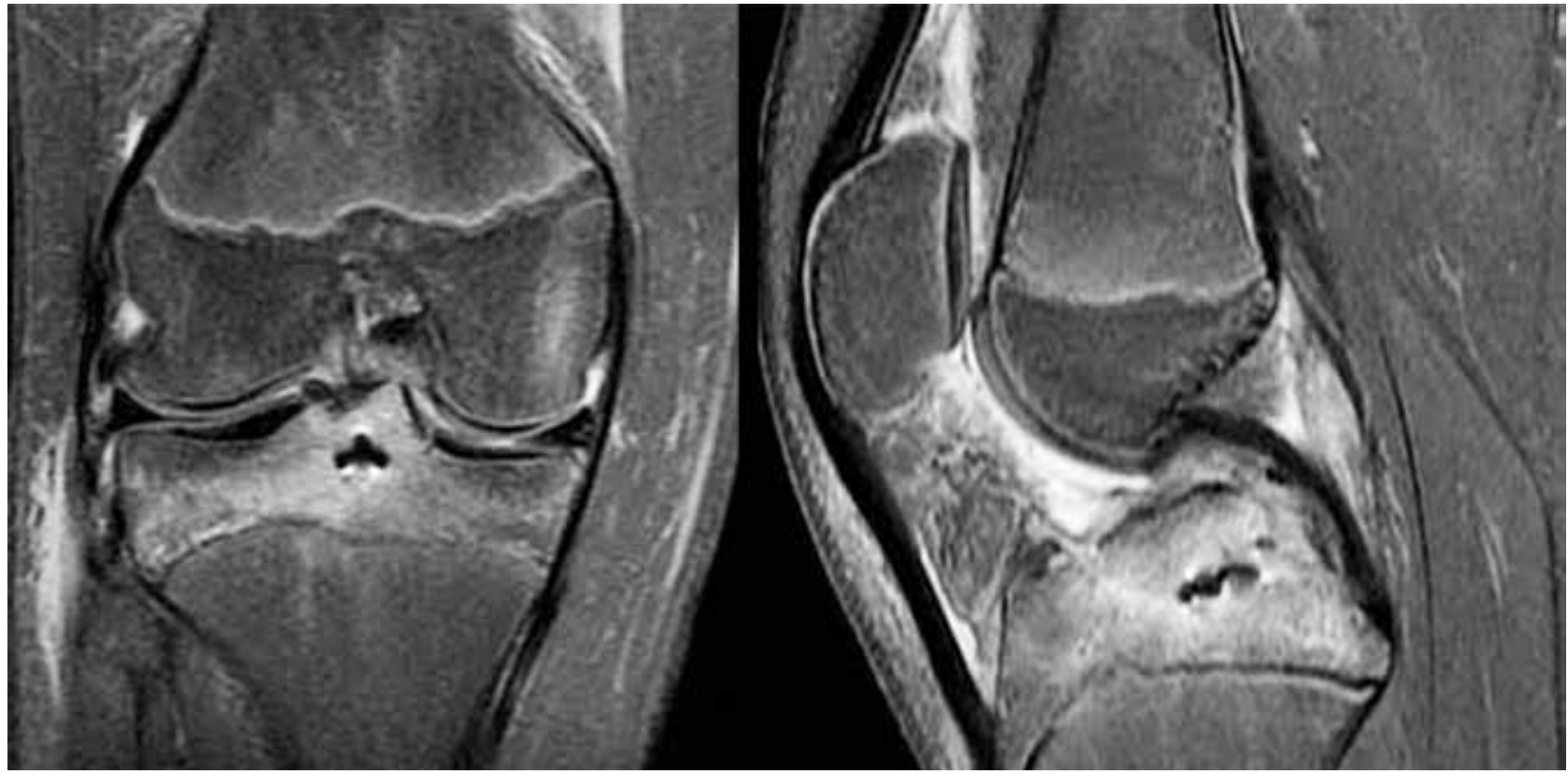

Şekil 5. Şekil 2'deki olgunun ameliyat sonrası 1. ay MR görüntüleri.

geçilmesidir. Fizisi geçerek daha stabil tespit sağladığını iddia edenlerle birlikte, fizisi geçmeyen tipte vida koyanlar da mevcuttur. İskelet olarak olgunlaşmamış tavşanlarda yapılan çalışma sonuçlarına göre, kesitsel olarak fizisin ortalama \%3'ünü kaplayan delme işlemlerinde problem saptanmazken, bu oran $\% 7$ ve üzerine çıktığında belirgin büyüme problemleri saptanmıştır. Transepifizyel tespit uygulanan çalışmalarda, nadir de olsa genu rekurvatum ve kısalık tarif edilmiştir. Fizisi geçen tespit yöntemleri uygulanırken dikkatli olunmalı ve fizise mümkün olduğunca az zarar verilmelidir. $[2,7,10,12,20,24-28]$

Son dönemlerde artroskopik olarak kırık tespitinde başsız kompresyon vidaları, Herbert vidaları, intra-artiküler buton tespiti, Kirschner telleri, sütür lasso cihazları geliş̧tirilmiş ve hepsinin uzun dönem sonuçları iyi olarak bildirilmiştir. ${ }^{[22-25]}$

\section{UZUN DÖNEM SONUÇLAR VE KOMPLIKASYONLAR}

2007 yılında yapılan bir biyomekanik çalışmaya göre sütür ve vida onarım yöntemleri incelenmiş, sütür tekniği tek ve dairesel yüklenme testlerinde daha güçlü saptanmıştır. Kullanılacak sütür üzerine yapılan çalışmalarda ise Polydioxanone II ${ }^{\circledR}$ (PDS II), Vicry ${ }^{\circledR}$ ve FiberWire $^{\circledR}$ incelenmiş, en etkin FiberWire ${ }^{\circledR}$ bulunmuştur. Vicry $\left.\right|^{\circledR}$ ile FiberWire ${ }^{\circledR}$ a yakın sonuçlar elde edilmiş ve Polydioxanone II ${ }^{\circledR}$ (PDS II) ile daha güçsüz sonuçlar alınmıştır. Günümüzde sütür materyallerindeki gelişmelerle birlikte, eminensia kırıklarında vidalı tespit ile kıyaslandığında iyi uzun dönem sonuçları alınabilmektedir (Şekil 5 ve 6). ${ }^{[5]}$

Yer değiştirmemiş ve kapalı olarak tedavi edilmiş hastalar ile tam redükte edilmiş ve cerrahi tedavi edilmiş hastaların kısa ve uzun dönem sonuçları, kısmi rezidüel laksisite haricinde gayet iyidir. ${ }^{[1,6,7,10,18]}$

Uzun dönem sonuçlarda en sık görülebilecek problem dizdeki laksisitedir. Dizdeki laksisite daha çok yaralanma esnasında oluşan bağ elongasyonuna bağlanmaktadır. Mükemmele yakın fonksiyonel sonuç bildiren birçok çalışmada, semptom oluşturmayan laksisite saptanmış ve Lachman testleri pozitif bulunmuştur. Bu çalışmalarda 3,5 ile 4,5 mm arası diz laksisitesi saptanmıştır. Erken çocuklukta daha tolere edilebilir olan bu laksisite, erişkinliğe doğru daha semptomatik hale gelmektedir. ${ }^{[7,10,12,20,21,26]}$

Bunun yanında; kırığın kaynamaması, yanlış kaynaması, eklem sertliği, ekstansiyon blokajı, epifiz yaralanması sonrası büyüme problemleri, menisküs lezyonları, enfeksiyon ve kırık hattındaki parçalanma, diğer komplikasyonlardır. ${ }^{[25,27]}$

Fizis yaralanması ile birlikte olan kırık tipleri, cerrahi olarak koyulan materyallerin fizise zarar vermesi, eşlik eden ve tedavi edilmeyen kollateral bağ yaralanmaları, 


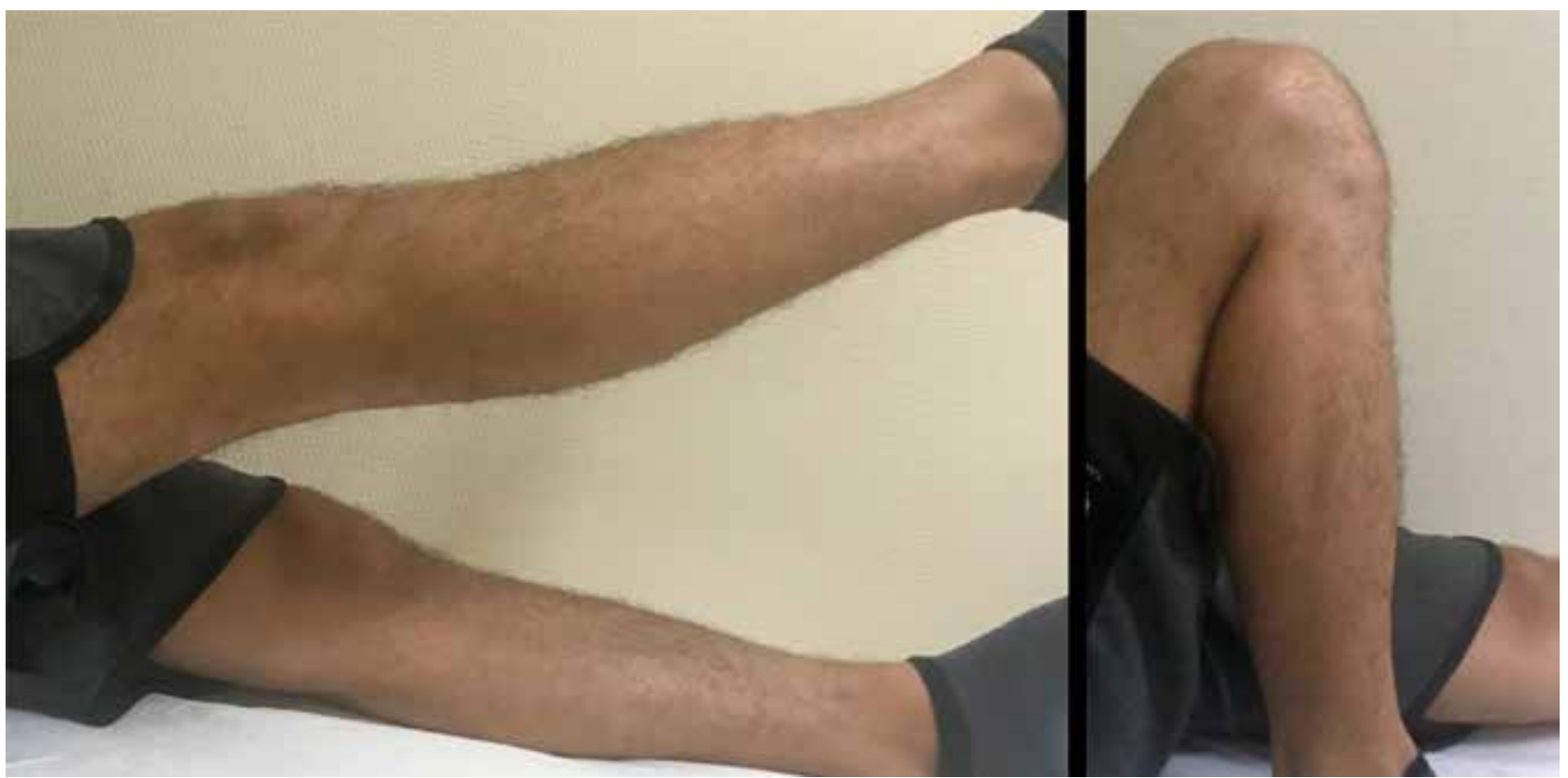

Şekil 6. Şekil 2'deki olgunun ameliyat sonrası 16. aydaki tam ekstansiyon ve fleksiyondaki görüntüleri.

büyüme problemleri oluşturarak rekurvatum deformitesine yol açabilir. ${ }^{[27-29]}$

Kırık hattındaki yanlış kaynama tam ekstansiyonda blokaj oluşturabilir. Semptomatik hastalarda yanlış kaynayan bu parça eksize edilerek ön çapraz bağ anatomik yerine dikilebilir. Erişkinlerde ise ön çapraz rekonstrüksiyonu düşünülebilir. ${ }^{[27-29]}$

Nadiren de olsa, kırık hattındaki kaynamama olgularında kırık yatağının kanayana kadar debridmanı sonrası greftleme ya da eksizyon sonrası ön çapraz bağ rekonstrüksiyonu uygulanabilir. ${ }^{[29,30]}$

Artrofibrozis ve eklem sertliği, daha çok cerrahi tedaviler sonrasında görülse de, geniş hemartroz ve immobilizasyon nedeniyle konservatif tedaviler sonrasında da görülebilir. Erken hareket, alçı ve atelden mümkün olduğunca hızlı sürede dinamik splinte geçilmesi, agresif fizik tedavi yöntemleri ilk üç aylık tedavi döneminde etkiliyken, üç aydan daha uzun süren eklem sertlikleri anestezi altında mobilize edilmelidir. ${ }^{[25,27]}$

\section{SONUÇ}

Sonuç olarak; eminensia kırıkları her ne kadar nadir görülseler de, son dönemde çocuklarda artan sportif aktivitelerle birlikte daha sık görülebilmektedir. Tanının atlanmaması için eminensia kırıkları akılda tutulmalı ve direkt grafilerde şüphe durumunda ileri görüntüleme yöntemleri istenmelidir. Kırığın anatomik redükte edilerek ön çapraz bağ bütünlüğü ve boyunun korunması, stabil bir tespitin sağlanması, tedavi sonucunu belirleyen en önemli etmenlerdir.

\section{KAYNAKLAR}

1. Meyers $\mathrm{MH}$, McKeever FM. Fracture of the intercondylar eminence of the tibia. J Bone Joint Surg Am 1959;41$A(2): 209-22$. Crossref

2. Larsen MW, Garrett WE, Delee JC, Moorman CT. Surgical management of anterior cruciate ligament injuries in patients with open physes. J Am Acad Orthop Surg 2006;14(13):73644. Crossref

3. Zaricznyj B. Avulsion fracture of the tibial eminence: treatment by open reduction and pinning. J Bone Joint Surg Am 1977;59(8):1111-4. Crossref

4. Binnet MS, Gürkan I, Yilmaz C, Karakas A, Çetin C. Arthroscopic fixation of intercondylar eminence fractures using a 4portal technique. Arthroscopy 2001;17(5):450-60. Crossref

5. Eggers AK, Becker C, Weimann A, Herbort M, Zantop T, Raschke MJ, Petersen W. Biomechanical evaluation of different fixation methods for tibial eminence fractures. Am J Sports Med 2007;35(3):404-10. Crossref

6. Owens BD, Crane GK, Plante T, Busconi BD. Treatment of type III tibial intercondylar eminence fractures in skeletally immature athletes. Am J Orthop (Belle Mead NJ) 2003;32(2):103-5.

7. Wiley JJ, Baxter MP. Tibial spine fractures in children. Clin Orthop Relat Res 1990;(255):54-60. Crossref 
8. Garcia A, Neer CS II. Isolated fractures of intercondyler eminence of the tibia. Am J Surg 1958;95(4):593-8. Crossref

9. Kendall NS, Hsu SY, Chan KM. Fracture of the tibial spine in adults and children. A review of 31 cases. J Bone Joint Surg Br 1992;74-B(6):848-52. Crossref

10. Iborra JP, Mazeau P, Louahem D, Diméglio A. Fractures of the intercondylar eminence of the tibia in children. Apropos of 25 cases with a 120 year follow up. Rev Chir Reparatrice Appr Mot 1999;85(6):563-73.

11. Lehman RA, Murphy KP, Machen MS, Kuklo TR. Modified arthroscopic suture fixation of a displaced tibial eminence fracture. Arthroscopy 2003;19(2):1-7. Crossref

12. Hunter RE, Willis JA. Arthroscopic fixation of avulsion fractures of the tibial eminence: technique and outcome. Arthroscopy 2004;20(2):113-21. Crossref

13. Griffith JF, Antonio GE, Tong CWC, Ming CK. Cruciate ligament avulsion fractures. Arthroscopy 2004;20(8):80312. Crossref

14. In $\mathrm{Y}$, Kim JM, Woo YK, Choi N-Y, Moon C-W, Kim M-W. Arthroscopic fixation of anterior cruciate ligament tibial avulsion fractures using bioabsorbable suture anchors. Knee Surg Sports Traumatol Arthosc 2008;16(3):286-9. Crossref

15. Oohashi $Y$. A simple technique for arthroscopic suture fixation of displaced fracture of the intercondylar eminence of the tibia using folded surgical steels. Arthroscopy 2001;17(9):1007-11. Crossref

16. Kocher MS, Micheli LJ, Gerbino PG, Hresko MT. Tibial eminence fractures in children: prevalence of meniscal entrapment. Am J Sports Med 2003;31(3);404-7. Crossref

17. Hayes JM, Masear VR. Avulsion fracture of the tibial eminence associated with severe medial ligamentous injury in an adolescent: a case report and review of the literature. Am J Sports Med 1984;12(4):330-3. Crossref

18. Reynders P, Reynders K, Broos P. Pediatric and adolescent tibial eminence fractures: arthroscopic cannulated screw fixation. J Trauma 2002;53(1):49-54. Crossref

19. Kim YM, Kim SJ, Yang JY, Kim K-C. Pullout reattachment of tibial avulsion fractures of the anterior cruciate ligament: a firm, effective suturetying method using a tensioner. Knee Surg Sports Traumatol Arthosc 2007;15(7):847-50. Crossref
20. Senekovic V, Veselko M. Anterograde arthroscopic fixation of avulsion fractures of the tibial eminence with a cannulated screw: fiveyear results. Arthroscopy 2003;19(1):54-61. Crossref

21. Fehnel DJ, Johnson R. Anterior cruciate injuries in the skeletally immature athlete: a review of treatment outcomes. Sports Med 2000;29(1):51-63. Crossref

22. Su W-R, Wang P-H, Wang H-N, Lin C-J. A simple, modified arthroscopic suture fixation of avulsion fracture of the tibial intercondylar eminence in children. J Pediatr Orthop B 2011;20(1):17-21. Crossref

23. Memisoglu K, Muezzinoglu US, Atmaca H, Sarman H, Kesemenli CC. Arthroscopic fixation with intra-articular button for tibial intercondylar eminence fractures in skeletally immature patients. J Pediatr Orthop B 2016;25(1):31-6. Crossref

24. Wiegand N, Naumov I, Vámhidy L, Nöt LG. Arthroscopic treatment of tibial spine fracture in children with a cannulated Herbert screw. Knee 2014;21(2):481-5. Crossref

25. Johnson DL, Durbin TC. Physeal-sparing tibial eminence fracture fixation with a headless compression screw. Orthopedics 2012;35(7):604-8. Crossref

26. Willis RB, Blakker C, Stoll TM, Paterson DC, Galpin RD. Long-term follow-up of anterior tibial eminence fractures. J Pediatr Orthop 1993;13(3):361-4. Crossref

27. Kieser DC, Gwynne-Jones D, Dreyer S. Displaced tibial intercondylar eminence fractures. J Orthop Surg (Hong Kong) 2011;19(3):292-6. Crossref

28. Mylle J, Reynders R, Broos P. Transepiphyseal fixation of anterior crutiate avulsion in a child: report of a complication and review of the literature. Arch Orthop Trauma Surg 1993;112(2):101-3. Crossref

29. Freedman KB, Glasgow SG. Arthroscopic roofplasty: Correction of an extension deficit following conservative treatment of a type III tibial avulsion fracture. Arthroscopy 1995;11(2):231-4. Crossref

30. Keys GW, Walters J. Nonunion of intercondylar eminence fracture of the tibia. J Trauma 1988;28(6):870-1. Crossref 